\title{
Jogo de MÍMICA PARA O ENSINO DE PROPAGAÇÃO DO CALOR: CONDUÇÃO, CONVECÇÃO E IRRADIAÇÃO
}

\author{
MIME GAME FOR THE TEACHING OF HEAT PROPAGATION: CONDUCTION, \\ CONVECTION AND IRRADIATION
}

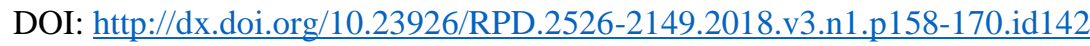

\begin{abstract}
Aline Mariane Alves de Amorim

Discente da Universidade

Federal do Acre (UFAC)

Bolsista do PIBID/Física

alinemariane001@gmail.co

$\underline{\mathrm{m}}$
\end{abstract}

\section{Joisilany Santos dos \\ Reis}

Discente da Universidade

Federal do Acre (UFAC)

Bolsista do PIBID/Física

joisilany.santos@gmail.com

\section{Victoria Cristina \\ Morais Oliveira}

Discente da Universidade

Federal do Acre (UFAC)

Bolsista do PIBID/Física

victoriacristina89@hotmail.c

$\underline{\mathrm{om}}$

\section{Bianca Martins Santos \\ Doutorado em Física (UFF) \\ Professora na Universidade \\ Federal do Acre (UFAC). \\ bianca8ms@gmail.com}

\begin{abstract}
Resumo: O trabalho apresenta resultados para o uso de recursos didáticos diferenciados para o ensino de física, com o objetivo de facilitar o processo de ensino e aprendizagem. A aula proposta inclui a apresentação teórica dos conteúdos, especificamente sobre, calor sensível, calor latente e os processos de transmissão de calor: condução, convecção e irradiação. Além disso, a metodologia inclui o uso de um experimento de baixo custo, a resolução de exercícios, a execução do jogo "Gesticulando a Física", e ao final, a aplicação do questionário investigativo sobre o recurso utilizado. A dinâmica proposta é mímica, inspirado no jogo "Imagem e Ação", no qual um dos jogadores da equipe deve fazer mímica para o restante, de fenômenos físicos sobre situações do cotidiano. O restante do grupo deve descobrir a situação representada e qual o processo de transmissão de calor envolvido. Os Bolsistas do Programa Institucional de Iniciação à Docência da área de Física (PIBID/Física) da Universidade Federal do Acre (UFAC) ministraram a aula à estudantes do $3^{\circ}$ ano do Ensino Médio em uma escola pública de Rio Branco-AC, dentro do projeto de extensão "Ciências na Escola: Experimentação e Teoria". Os resultados mostram que a utilização da sequência didática proposta estimulou aos alunos à compreensão e fixação do conteúdo de forma facilitada e divertida. Além disso, a dinâmica proposta revelou ser um recurso promissor para o ensino de física.
\end{abstract}

Palavras-chave: Ensino de física; Propagação de calor; Mímica.

\begin{abstract}
The work presents results for the use of differentiated didactic resources for the teaching of physics, with the objective of facilitate the teaching and learning process. The proposed class includes the theoretical presentation of the contents, specifically about sensible heat, latent heat and the processes of heat transmission: conduction, convection and irradiation. In addition, the methodology includes the use of a low-cost experiment, the resolution of exercises, the execution of the game "Gesturing the Physics", and at end, the application of the investigative questionnaire on the resource used. The proposed dynamic is mimicry, inspired in the game "Image and Action", in which one of the players of the team must to mimic for the remainder, from physical phenomena about everyday situations. The rest of the group should discover the situation represented and what is the heat transfer process involved. The scholarship holders from Institutional Program for Initiation to Teaching of the physics (PIBID/Physics) from Federal University of Acre (UFAC) ministered class to the students from 3rd year of high school in a public school in Rio Branco-AC, inside the extension project "Sciences in the School: Experimentation and Theory". The results show that the use of the proposed didactic sequence stimulated students to understand and fixation of content in an easy and fun way. In addition, the proposed dynamics revealed to be a promising resource for physics teaching.
\end{abstract}

Keywords: Physics teaching; Heat propagation; Mimicry. 


\section{INTRODUÇÃO}

A escola como instituição de ensino desempenha um papel fundamental na sociedade, por meio dela o ser humano tem acesso a informação, conhecimento científico, vida em sociedade, entre outras finalidades de suma importância. Entretanto, o ambiente que deveria ser tomado como encantador por seu caráter de descoberta, tem sido negligenciado por muitos estudantes, por estarem envolvidos ao mundo tecnológico, concentrados nos aplicativos de entretenimento e redes sociais. Neste sentido, enquanto os estudantes estão a cada dia mais inseridos no mundo tecnológico, a grande maioria dos professores ainda mantêm o método tradicional de ministrar aulas (BEZERRA, 2009). Estas duas realidades contrabalançadas, resultam em alunos desmotivados, causando o desinteresse dos mesmos, no qual optam por estarem desatentos nas aulas em relação aos conteúdos lecionados (ROSA, 2015).

Outros fatores agravam este cenário. Grande parte dos professores são limitados a desenvolver aulas diferenciadas, por critérios metodológicos adotados nas escolas. Por outro lado, alguns professores alegam não ter tempo para preparação de metodologias inovadoras por possuírem uma carga horária extensa (BAIÃO, 2013). Particularmente, o presente trabalho se concentra na componente curricular de física, que é uma das disciplinas consideradas "temida" e "difícil" pelos discentes, basicamente por fazer uso da linguagem matemática como ferramenta para descrevê-la (RICARDO, 2007; MORAES, 2009).

Nesse caso, o professor exerce o papel fundamental de tornar a aula mais dinâmica e agradável, apresentando a física de forma fascinante por seu caráter de descoberta e de descrever os fenômenos da natureza presentes no dia a dia, de forma à desmistificar o senso comum de ser uma disciplina puramente matematizada. Neste sentido, encontra-se na literatura várias pesquisa relacionadas ao ensino de física com o uso do teatro (MEDINA, 2010), cinema (NAPOLITANO, 2005), tirinhas (CARUSO, 2002), jogos (PEREIRA, 2009), entre outros. Entretanto, a pesquisa que resulta no desenvolvimento de novas metodologias para o ensino de ciências, em geral, não tem chegado às escolas de educação básica de forma significativa.

Neste sentido, o presente trabalho propõem uma atividade didática para o ensino de física, sobre os processos de transmissão de calor, além de apresentar resultados sobre a aplicação da aula proposta durante o projeto de extensão "Ciências na Escola: Experimentação e Teoria”. O projeto de extensão consiste na realização de minicursos de Química, Física e Biologia à alunos do terceiro ano do ensino médio de escolas públicas de Rio Branco-AC, sobre temas abordados no Exame Nacional do Ensino Médio (ENEM). Tal projeto teve como objetivo 
promover a aproximação entre a universidade e a escola de educação básica; desenvolver a autonomia do acadêmico na produção do próprio material didático para aulas teóricas e práticas, bem como a regência em sala de aula; e proporcionar a interação de estudantes e professores do ensino médio com estudantes e professores da universidade.

Cabe ressaltar que os professores de Química, Física e Biologia da universidade, responsáveis pelo projeto de extensão, orientam os graduandos das respectivas áreas no planejamento das aulas diferenciadas. Assim, o projeto propõe fomentar discussões sobre a formação de professores de ciências (CARVALHO, 2009), bem como refletir sobre o "para quê ensinar?" e “como ensinar?” (ROSA, 2007). Com a presente ação, pretendia-se aproximar a escola de educação básica e a universidade, para viabilizar a formação inicial e continuada dos professores de física, promovendo a articulação entre o planejamento e a aplicação de novas metodologias de ensino.

Dentre a diversidade de recursos disponíveis para o ensino da componente curricular de física, o presente trabalho se concentra no estudo do uso de jogos, especificamente sobre mímica, com objetivo de facilitar a compreensão e fixação dos conteúdos estudados. Com este intuito, o uso de jogos de mímica na sala de aula auxilia a concentração, desenvolve a imaginação e a coordenação motora dos alunos, tornando o aprendizado divertido e eficaz (MOURA, 1988; MOYLES, 2002).

Vale ressaltar que segundo os Parâmetros Curriculares Nacionais - PCN+,

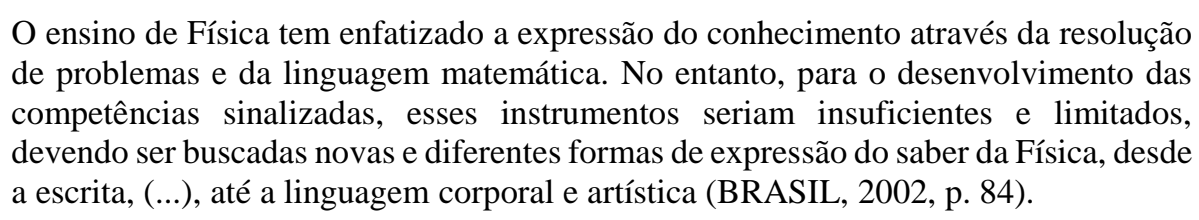

Observe que o uso da linguagem corporal e artística é incentivado, bem como o trabalho em grupo, de forma a construir no estudante um ser humano ativo, crítico e participativo no mundo em que vive. Crescentemente, percebe-se uma forte tendência de alguns professores desenvolverem a imaginação, criatividade, persistência, vontade e gosto pela atividade docente criando aulas dinâmicas e prazerosas. Vale mencionar que tal prática deve ser incentivada, na busca de um ensino de qualidade. Ao professor, cabe à arte de despertar a curiosidade no aluno e ainda organizar a sala de aula, mantendo a disciplina e possibilitando a construção do conhecimento por seus alunos. Entretanto, este processo, parece simples para quem não conhece o ambiente da sala de aula, mas na realidade, conseguir despertar a curiosidade dos alunos, manter a atenção e a disciplina são tarefas complicadas. E por este motivo, deve-se 
procurar a inovação na forma de ensinar física, seja nas metodologias utilizadas ou nos recursos didáticos desenvolvidos.

Uma das vantagens para o uso do jogo de mímica para o ensino de física refere-se ao fato de tornar a aula mais agradável e fortalecer a relação professor-aluno e aluno-aluno, estabelecendo um ambiente de trabalho mais sociável. Conforme a teoria de educação de NOVAK (1981, p. 252) baseada no pensamento de que a educação é o conjunto de experiências (cognitivos, afetivos e psicomotores) que contribuem para o engrandecimento (empowerment) do indivíduo para lidar com a vida diária.

Vale reforçar que uma das formas do sujeito entender e estar inserido no mundo que o cerca origina-se na imitação: das pessoas, dos sons, das formas, entre outros. Imitar é uma forma de adquirir conhecimento através do significado atribuído à determinados gestos, como exemplo, as expressões faciais e as diversas formas de entonação ao pronunciar as palavras. Além disso, segundo Vygotsky,

É na atividade de jogo que a criança desenvolve o seu conhecimento do mundo adulto
e é também nela que surgem os primeiros sinais de uma capacidade especificamente
humana, a capacidade de imaginar (...). Brincando a criança cria situações fictícias,
transformando com algumas ações o significado de alguns objetos. (VYGOTSKY,
1998, p.122).

Detalhes sobre o projeto de extensão em que a metodologia proposta foi aplicada, o experimento utilizado e as regras do jogo são apresentados a seguir.

\section{Metodologia}

A metodologia utilizada consiste na aplicação de uma sequência didática sobre o estudo da termologia e calor, especificamente sobre, calor sensível, calor latente e os processos de transmissão de calor: condução, convecção e irradiação. A atividade fez parte do conjunto de ações desenvolvidas pelos graduandos de Licenciatura em Física da Universidade Federal do Acre (UFAC) que participam do Programa Institucional de Bolsa de Iniciação à Docência PIBID/Física. A atividade também fez parte do projeto de extensão "Ciências na Escola: Experimentação e Teoria", que ocorreu no contraturno das aulas regulares para alunos de $3^{\circ}$ ano do Ensino Médio de uma escola estadual localizada na cidade de Rio Branco-AC. O projeto de extensão oferecia durante uma semana, aulas de física, química e biologia, planejadas e ministradas por graduandos de licenciatura nas respectivas áreas, com a supervisão de professores da universidade e da escola de educação básica envolvida. O objetivo geral do projeto era proporcionar a vivência da docência partindo de uma atuação prática na elaboração 
de materiais didáticos associado ao preparo de aulas teóricas e experimentais, bem como a regência da atividade proposta, a partir da aproximação entre a universidade e a escola.

Os alunos da escola foram convidados a participarem da atividade de extensão com o foco na prova do ENEM. A atividade era opcional para os estudantes e não era recompensada com pontos extras, frequentaram realmente aqueles que queriam aprender. A aula aplicada baseava-se na sequência didática exibida no Quadro 1.

Quadro 1 - Sequência Didática

\begin{tabular}{c|l}
\hline Etapa & Descrição da Sequência Didática \\
\hline $1^{\circ}$ & Apresentação dos conceitos teóricos sobre o tema com exemplos do cotidiano. \\
\hline $2^{\circ}$ & Uso de experimento sobre propagação de calor por convecção. \\
\hline $3^{\circ}$ & Resolução de questões do ENEM. \\
\hline $4^{\circ}$ & Realização do jogo de mímica "Gesticulando a Física”. \\
\hline $5^{\circ}$ & Aplicação de um questionário para coleta de dados sobre a atividade. \\
\hline
\end{tabular}

A primeira parte da sequência didática descrita no Quadro 1 refere-se à apresentação dos conceitos de calor sensível, calor latente e os processos de transmissão de calor: condução, convecção e irradiação. Esta foi ministrada na forma de uma aula expositiva, dialogada e participativa, com o uso do quadro, apostila, e datashow. Utilizou-se exemplos do dia a dia para possibilitar uma aprendizagem que estabelecesse conexão entre a teoria e o cotidiano. Dentro da sequência didática, foi realizado um experimento sobre inversão térmica para demonstrar na prática a teoria. A terceira etapa da sequência didática incluía a discussão e resolução das questões do ENEM sobre o assunto proposto. A quarta etapa se deu para fins de fixação do conteúdo, com a aplicação do jogo de mímica "Gesticulando a Física". Ao final da aula, foi aplicado um questionário, apresentado no Apêndice, que tinha como propósito investigar a opinião dos alunos em relação aula aplicada.

$\mathrm{O}$ experimento proposto na sequência didática demonstra o fenômeno de inversão térmica, ao colocar duas garrafas acopladas por suas tampas, vazadas no meio, para possibilitar o contato entre os fluidos e a movimentação dos mesmos quando a situação física permiti. Na Figura 1 é apresentado o esquema ilustrativo do experimento. Na parte (a) da figura são representadas duas garrafas transparentes, uma com líquido frio de cor azul e outra com líquido quente de cor vermelha.

Para o experimento utilizou-se quatro garrafas, duas com água fria e duas com água quente. Na oportunidade, utilizou-se água com corante vermelho aquecida no microondas da escola e água gelada com corante azul mantida na geladeira da escola. O fenômeno físico envolvido é visualizado quando as Situações 1 e 2, ilustradas respectivamente na Figura 1 - 
parte (b) e (c), são reproduzidas. A parte (b) da figura caracteriza a Situação 1, onde a garrafa com o fluido quente (de cor vermelha) é colocado na parte superior da garrafa com o fluido frio (de cor azul). Neste caso não há troca de calor, e após alguns minutos, os líquidos permanecem estáticos. Na parte (c) indica a Situação 2, onde a garrafa com fluido frio (de cor azul) é colocado na parte superior da garrafa com fluido quente (de cor vermelha). Nesta última situação é possível observar a troca de calor, e após alguns minutos, os líquidos se misturam até atingir o equilíbrio térmico (de cor roxa).

Com o experimento, os estudantes podem observar o processo de troca de calor por convecção, e fazer a analogia com o exemplo prático do ar condicionado e responder a seguinte pergunta "Por que o ar condicionado deve ser instalado no alto?”. A explicação física está relacionada ao processo de troca de calor por convecção, pois a massa de ar frio (que é mais densa) desce e a massa de ar quente (que é mais leve) sobe. No experimento, tal processo é visualizado na Situação 2, quando o líquido azul (frio) desce e o líquido vermelho (quente) sobe, provocando a mistura dos fluidos até atingir o equilíbrio. Ao colocar a garrafa de água quente sobre a de água fria, nada acontece, os líquidos não se misturam. Porém, no caso contrário, ao colocar a garrafa de água fria sobre a de água quente, os líquidos se misturam. Os materiais utilizados no experimento foram: dois pares de garrafas pet com as tampas vazadas e coladas por fita isolante e/ou cola quente; água quente e fria; e duas tonalidades diferentes de corantes.

Figura 1 - Ilustração do experimento sobre o processo de troca de calor por convecção.

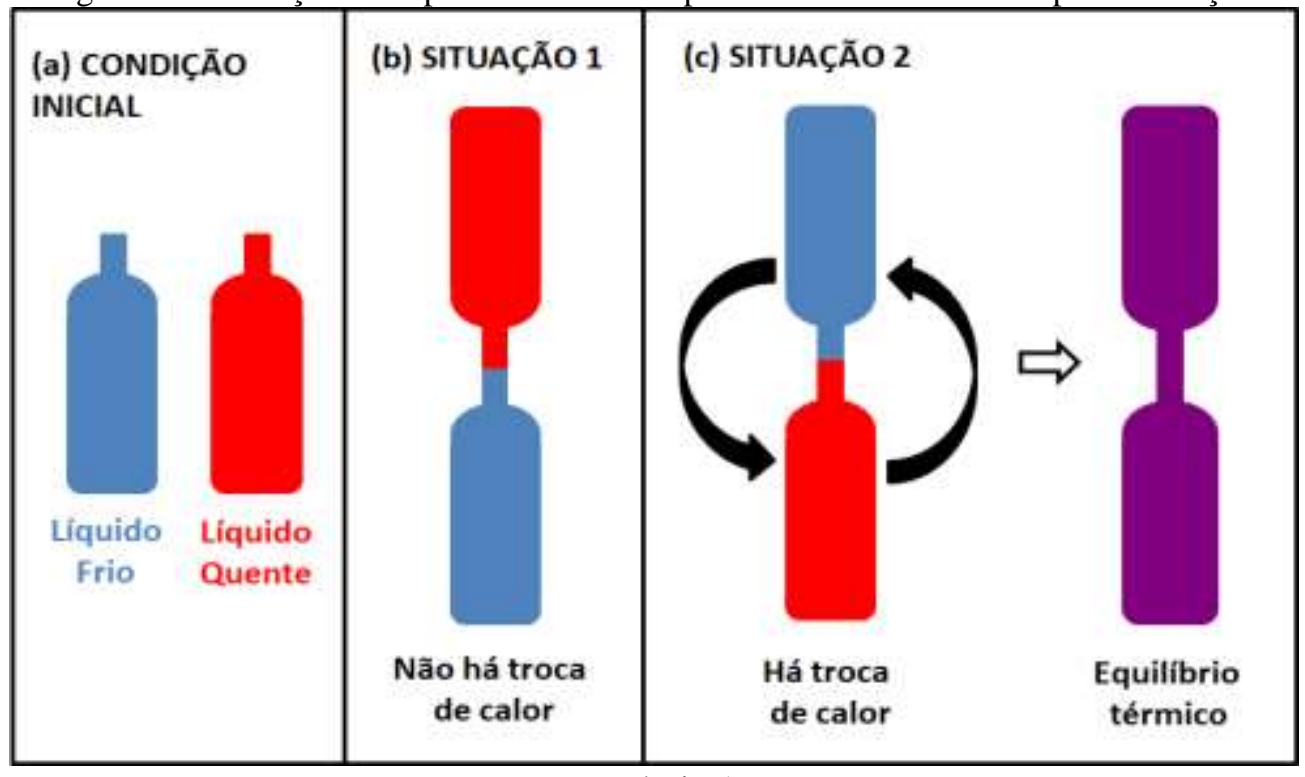

Fonte: Próprio Autor. 
O jogo "Gesticulando a Física" foi inspirado na conhecido jogo "Imagem e Ação", para ser jogado em equipes. Na presente proposta, a turma foi dividida em três grupos e cada grupo deveria apontar um representante. Os representantes de cada grupo retiraram uma carta do baralho sem identificar a figura nela representada. As imagens nas cartas exemplificam situações do cotidiano. Em seguida, o representante do grupo deveria fazer mímica da situação descrita na carta para o restante de sua equipe, que por sua vez deveria descobrir qual situação estava sendo gesticulada, além de acertar o processo de transmissão de calor envolvido.

Determinada a situação exemplificada na carta, o grupo teria disponível o tempo de um minuto para responder qual o processo de transmissão de calor estava envolvido com a situação do cotidiano em questão. Por exemplo, se o jogador retirasse a foto do microondas, o grupo teria que descobrir através da mímica que a carta se tratava do microondas. Na sequência, o grupo deveria identificar qual o processo de transmissão de calor envolvido, neste caso, o da irradiação. Na Figura 2 são apresentadas as cartas relacionadas ao processo de condução, onde a transferência de calor ocorre através do contato. Na Figura 3 são apresentadas imagens que representam o processo de convecção, no qual o calor é transferido através do transporte de matéria. E por fim, na Figura 4, são exibidos desenhos de situações relacionadas ao processo de irradiação, onde a troca de calor ocorre através da radiação eletromagnética.

Figura 2: Cartas relacionadas ao processo de condução usadas no jogo "Gesticulando a Física".

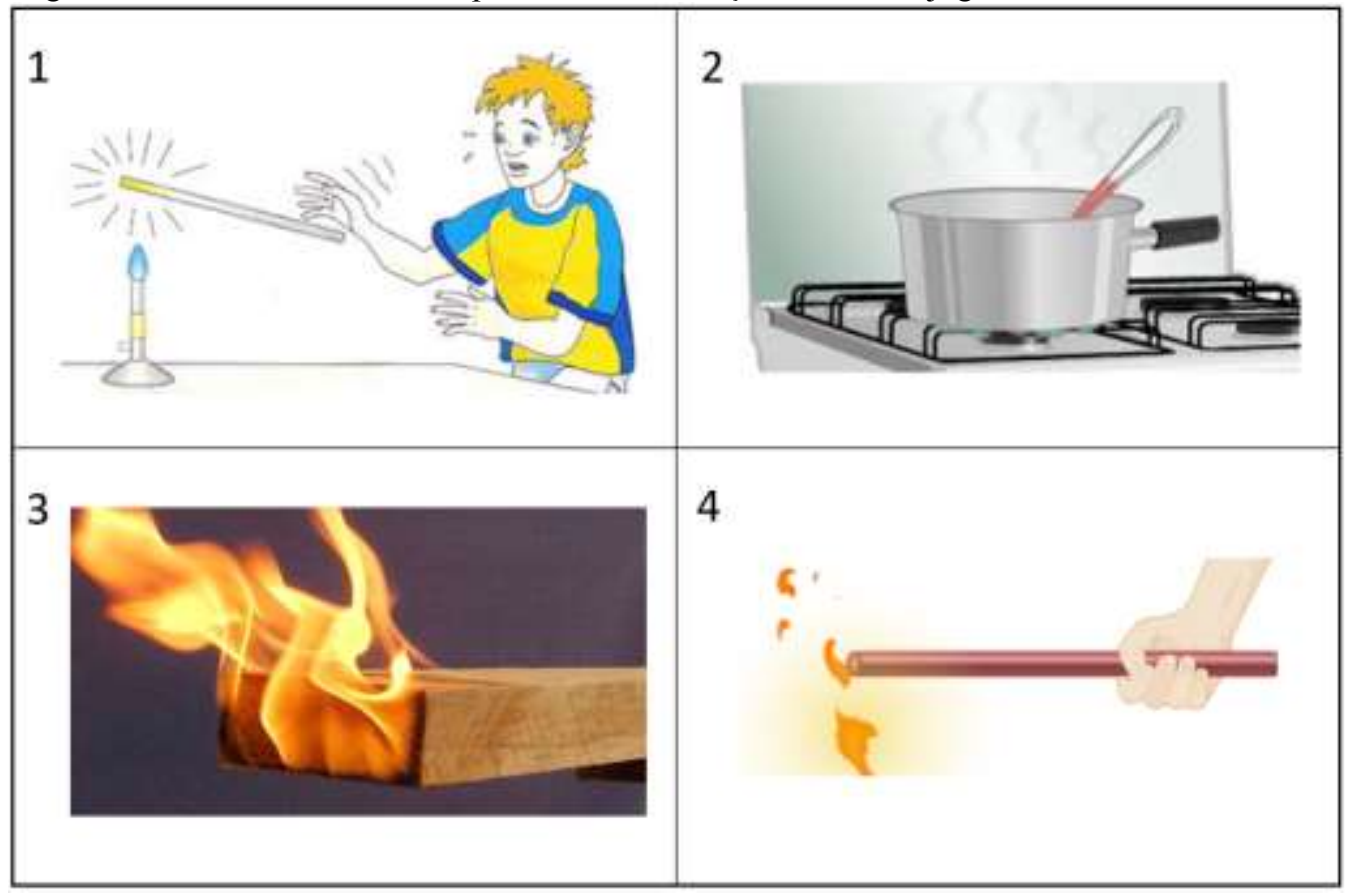

Fonte: (1) http://www.aulas-fisica-quimica.com/imagens/7e_11_01.png;

(2) sobrefisica.files.wordpress.com/2011/05/gab-3.png;

(3) http://www.sobiologia.com.br/figuras/Oitava_quimica/fogo2.jpg;

(4) http://tecciencia.ufba.br/articles/0001/6264/conducao.png. 
Figura 3: Imagens que representam o processo de convecção usadas no jogo "Gesticulando a Física".

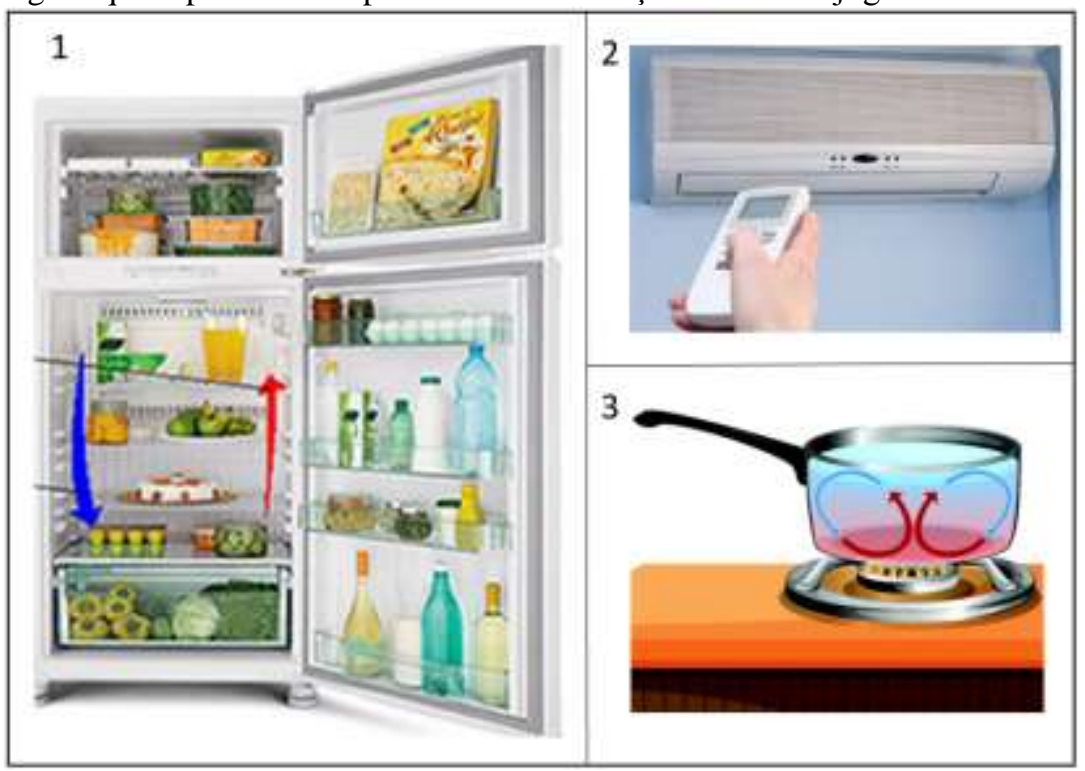

Fonte: (1) http://alunosonline.uol.com.br/upload/conteudo_legenda/5df9b08e85eef5e9770cd8e8d08ad692.jpg;

(2) http://observatoriodeourofino.com.br/wordpress/wp-content/uploads/2018/01/ar-condicionadocondominio.jpg;

(3) http://mundoeducacao.bol.uol.com.br/upload/conteudo/convec\%C3\%A7\%C3\%A3o.jpeg

Figura 4: Desenhos de situações relacionadas ao processo de irradiação usadas no jogo "Gesticulando a Física".

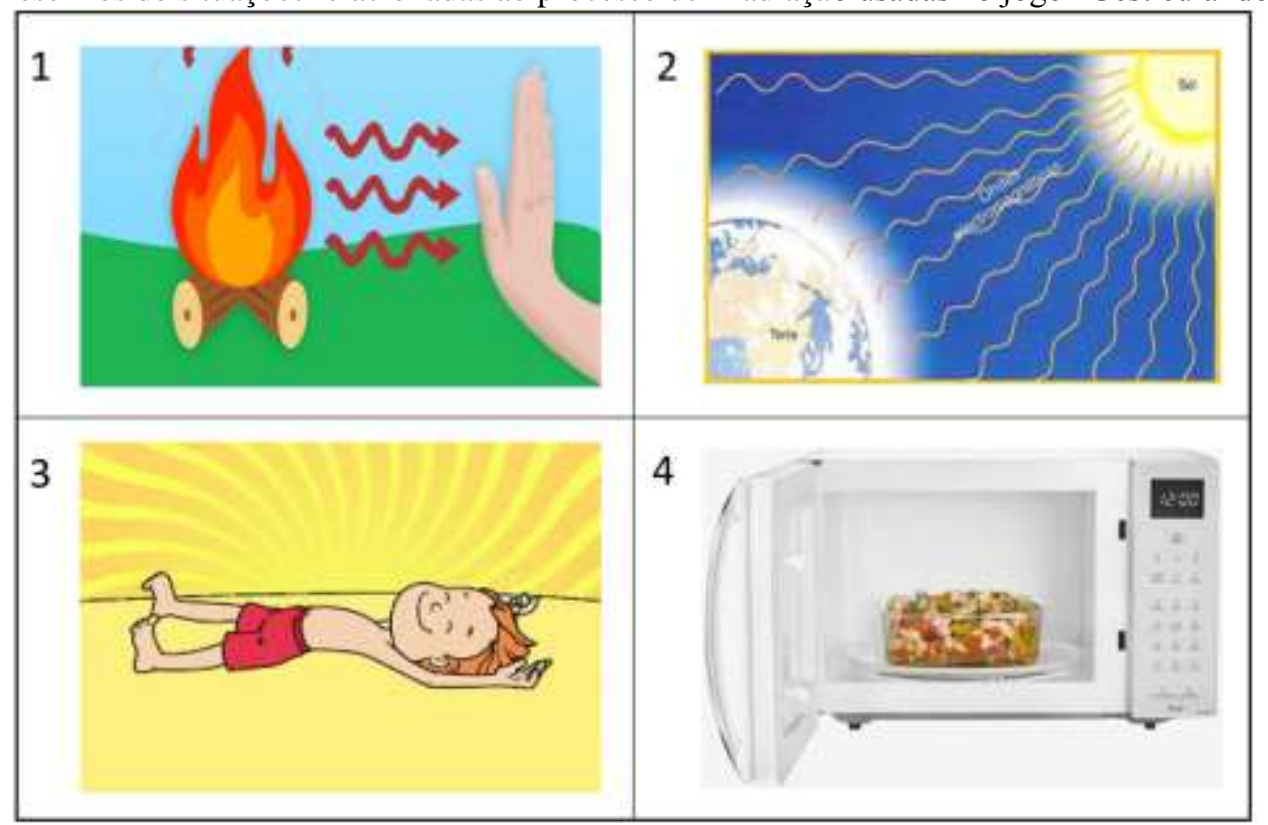

Fonte: (1) http://2.bp.blogspot.com/-cSIBT3IOpC0/UGedYtQPbUI/AAAAAAAAF6g/RKHkzTAUGI/s1600/f44.bmp;

(2) http://www.aulas-fisica- quimica.com/imagens/7e_11_03.jpg;

(3) http://cdn5.colorir.com/desenhos/color/201707/crianca-tomando- sol-natureza- estacoesdo-ano- 1339981.jpg;

(4) http://nedmed.info/images/img_138757-195.jpg

O planejamento da aula foi realizado com a orientação da coordenadora do PIBID/Física-UFAC. A fase de preparação da aula envolvia a escolha do tema. Neste ponto, como o projeto de extensão tinha o foco em fazer uma revisão para o ENEM, foi escolhido um 
dos temas cobrados com maior frequência em edições anteriores do exame, neste caso, Calor. Foi elaborado uma apostila curta de cinco páginas para ser utilizado durante a aula, bem como a preparação do experimento das garrafas e a elaboração do jogo "Gesticulando a Física", que envolvessem materiais de baixo custo ou recicláveis. Os materiais utilizados no jogo foram: cartas de baralho, impressão das imagens apresentadas nas Figuras 2, 3 e 4, cola e tesoura. As imagens impressas foram coladas nas cartas de baralho. Como alternativa às cartas de baralho, pode-se colar as imagens em papel cartão ou qualquer outro material que não permita a identificação da imagem da carta através do verso.

\section{Resultados}

Os resultados aqui apresentados são referentes à aplicação da sequência didática proposta. O total de estudantes que participaram da atividade e que responderam o questionário, apresentado no Apêndice, foram de 21 alunos. No decorrer do jogo, ficou claro que os estudantes se divertiram fazendo mímica, porém tiveram grande dificuldade em imaginar como representar as situações do cotidiano e identificar qual o tipo de transmissão de calor envolvido. Como exemplo, mostraram dificuldades em imitar as situações: esquecer uma colher dentro da panela, usar o ar condicionado ou esquentar uma comida no micro-ondas; bem como em relacioná-las respectivamente aos processos de condução, convecção e irradiação. Mediante tal dificuldade, a primeira rodada foi realizada com ajuda do professor. A partir da segunda rodada, após os grupos descobrirem a situação do cotidiano gesticulada, aos estudantes foram exigidos o tempo de um minuto para dar a resposta sobre qual processo de transmissão de calor estava relacionado a situação. Neste momento, foi possível observar que apesar da timidez, houve grande interação entre os estudantes. Analisando todo o contexto, o jogo "Gesticulando a Física" teve bom aproveitamento, promovendo a discussão dos conteúdos entre os estudantes.

Verificou-se ainda que o uso de jogos produz uma nova visão sobre a física, modificando o senso comum de que os estudantes têm aversão à disciplina. Viabilizou ainda o trabalho do conteúdo de transmissão de calor de forma prática, através do lúdico. Como o uso de jogos e atividades experimentais, as aulas de física tornam-se atrativas e prazerosas. $\mathrm{Na}$ presente pesquisa foi possível ver através do projeto de extensão que uma aula dinâmica chama a atenção dos alunos, tornando interessante os conceitos sobre tema abordado.

Um questionário investigativo, veja o Apêndice, foi aplicado no final da atividade. A primeira pergunta do questionário estava relacionada sobre o que os alunos acharam da aula. As opções para essa pergunta eram: Ótima, Boa, Regular ou Ruim. Verificou-se que 90\% dos 
alunos aprovaram a aula como ótima, e 10\% (apenas dois alunos) consideraram a aula boa. As perguntas seguintes investigavam a opinião dos participantes da pesquisa sobre o uso do jogo proposto e da metodologia utilizada com o experimento das garrafas, no qual $95 \%$ dos alunos afirmaram que estes recursos facilitam a compreensão dos conteúdos, enquanto que um estudante (5\%) deixou a questão em branco. No Quadro 2 são apresentados alguns comentários dos alunos sobre o porquê o uso do experimento das garrafas e do jogo de mímica facilitaram a compreensão dos conteúdos. Observe no quadro que os estudantes conseguiriam compreender o conteúdo e ver a física aplicada no seu dia a dia de forma divertida.

Quadro 2 - Comentários dos participantes da pesquisa ao questionário aplicado.

Justificativa dos alunos que apontaram o uso do experimento das garrafas e do jogo de mímica como recursos que facilitaram a compreensão dos conteúdos.

Aluno 1: $\quad$ “...através do mesmo conseguimos visualizar o fenômenos físico se divertindo.”

Aluno 2: “...haverá uma interação entre os conteúdos, para que a aula não fique chata.”

Aluno 3: “...podemos ver e compreender melhor os conteúdos.”

Fonte: Próprio autor

Com a pesquisa verificou-se que recursos diferenciados para o ensino de física demonstraram ser ferramentas interessantes para facilitar o processo ensino/aprendizagem. Aponta-se ainda a importância da utilização de recursos didáticos no qual os estudantes participem ativamente das aulas, como exemplo: jogos, cinema, teatro e tirinhas, aulas experimentais, entre outros.

\section{CONSIDERAÇões FinAIS}

A pesquisa propõe a aplicação de uma aula para componente curricular de física sobre transmissão de calor por condução, convecção e irradiação para alunos do $3^{\circ}$ Ano do Ensino Médio de uma escola pública localizada na cidade de Rio Branco-AC. A aula inclui o uso de um experimento simples e o jogo de mímica "Gesticulando a Física”. Para o jogo a turma foi dividida em grupos e um jogador deveria fazer mímica sobre uma situação do cotidiano que envolvesse um dos processos de transmissão de calor, e o grupo deveria acertar qual a situação do cotidiano estava sendo representada e na sequência qual o processo relacionado, de condução, convecção ou irradiação.

Os resultados apontados pelos estudantes ao questionário investigativo comprovou que o jogo de mímica auxiliou e motivou os alunos, facilitando a compreensão dos fenômenos físicos associado ao assunto aplicado, tornando a aula mais interativa e atraente para os alunos, facilitando o processo de ensino/aprendizagem. Desenvolvendo assim o cognitivo dos estudantes, o raciocínio lógico, a socialização, trabalhando a timidez, e a coordenação motora. 
Verificou-se por meio do questionário que a atividade alcançou seu objetivo, mostrando que a física pode ser ensinada através de jogos ou qualquer outro recurso, quando adaptada para a realidade da classe.

Indica-se aos professores da componente curricular de física o uso de recursos didáticos diferenciados do tradicional, neste sentido a presente pesquisa traz como contribuição o uso do jogo de mímica "Gesticulando a Física". Observando que tais recursos contribuem para facilitar a compreensão dos fenômenos físicos abordados, principalmente em saber diferenciar cada um dos processos de transmissão de calor envolvidos em situações do cotidiano.

\section{APÊNDICE}

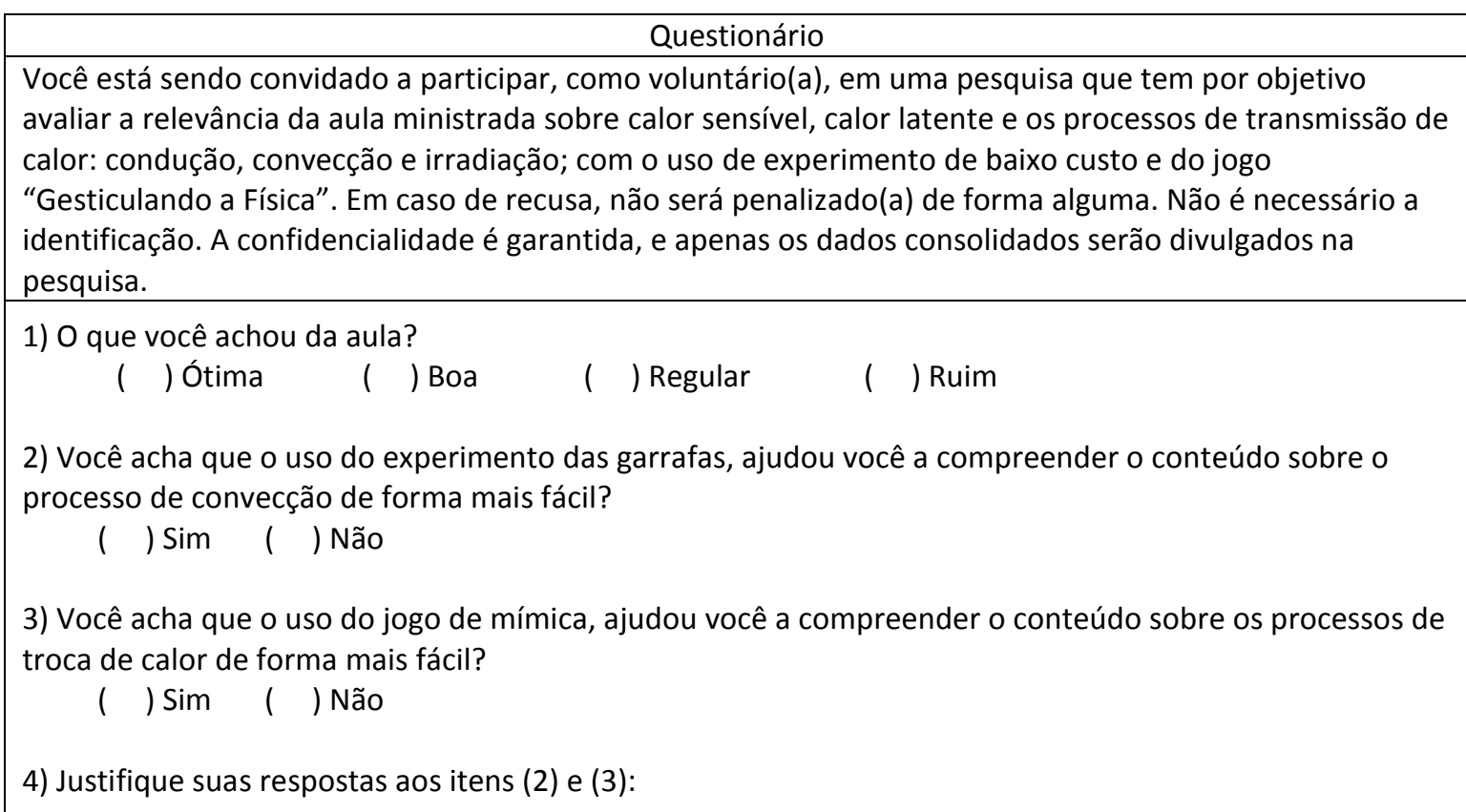

4) Justifique suas respostas aos itens (2) e (3):

\section{REFERÊNCIAS}

BAIÃO, L. P. M.; CUNHA, R. G. Doenças e/ou disfunções ocupacionais no meio docente: uma revisão de literatura. Revista Formação@Docente, Belo Horizonte, v. 5, N. 1, jan/jun 2013. Disponível em:

<http://www3.izabelahendrix.edu.br/ojs/index.php/fdc/article/view/344/0>. Acessado em 03 mar. 2018.

BEZERRA, D. P.; GOMES, E. C. S.; MELO, E. S. N.; SOUZA, T. C. A evolução do ensino da física - perspectiva docente. Scientia Plena, v. 5, p. 094401-1 - 094401-8, 2009. Disponível em: <https://scientiaplena.emnuvens.com.br/sp/article/viewFile/672/342〉. Acessado em 03 mar. 2018. 
BRASIL. PCN+: Orientações educacionais complementares aos Parâmetros Curriculares Nacionais, Ciências da Natureza, Matemática e suas Tecnologias. Brasília: Ministério da Educação e Cultura, 2002.

CARUSO, F.; CARVALHO, M.; SILVEIRA, M. C. Uma proposta de ensino e divulgação de ciências através dos quadrinhos. Ciência \& Sociedade, Rio de Janeiro, v. 8, 2002. Disponível em: 〈http://cbpfindex.cbpf.br/publication_pdfs/cs00802.2006_12_08_10_29_32.pdf>.

Acessado em 03 mar. 2018.

CARVAlHO, A. M. P.; PÉREZ, D. G.; Formação de Professores de Ciências: tendências e inovações. São Paulo: Cortez Editora, 9 Ed., 2009.

MEDINA, M. O teatro como ferramenta de aprendizagem da física e de problematização da natureza da ciência. Caderno Brasileiro Ensino Física, v. 27, n. 2, p. 313-333, ago. 2010. Disponível em: <https://periodicos.ufsc.br/index.php/fisica/article/view/21757941.2010v27n2p313>. Acessado em 03 mar. 2018.

MORAES, J. U. P. A visão dos alunos sobre o ensino de física: um estudo de caso. Scientia Plena, v. 5, N. 11, p. 114809-1 - 114809-7, 2009. Disponível em: <https://www.scientiaplena.org.br/sp/article/view/736>. Acessado em 03 mar. 2018.

MOURA, M. O. (Org.) A série busca no jogo: do lúdico na matemática.14 Ed. São Paulo: Editora Ática, 1988.

MOYLES, J. R. Só brincar? O papel do brincar na educação infantil. Tradução: Maria Adriana Veronese. Porto Alegre: Artmed, 2002.

NAPOLITANO, M. Como usar o cinema na sala de aula. São Paulo: Contexto, 2005.

NOVAK, J. D. Uma teoria de educação. São Paulo: Pioneira, 1981. Tradução de M. A. Moreira do original A theory of education, Cornell University Press, 1977.

PEREIRA, R. F.; FUSINATO, P. A.; NEVES, M. C. D. Desenvolvendo um jogo de tabuleiro para o ensino de física. In: ENCONTRO NACIONAL DE PESQUISA EM EDUCAÇÃO EM CIÊNCIAS VII Enpec, Anais... Florianópolis, 8 de Novembro de 2009. Anais. Disponível em: 〈http://posgrad.fae.ufmg.br/posgrad/viienpec/pdfs/1033.pdf>. Acessado em 03 mar. 2018.

RICARDO, E. C.; FREIRE, J. C.A. A concepção dos alunos sobre a física do ensino médio: um estudo exploratório. Revista Brasileira de Ensino de Física, v. 29, n. 2, p. 251-266, 2007. Disponível em: 〈http://www.scielo.br/pdf/rbef/v29n2/a10v29n2.pdf >. Acessado em 03 mar. 2018.

ROSA, C. W.; ROSA, Á. B. Ensino da Física: tendências e desafios na prática docente. Revista Iberoamericana de Educación, v. 43, N. 1, p. 1 -12, 2007, Número especial. Disponível em: <https://rieoei.org/RIE/article/view/2343>. Acessado em 03 mar. 2018.

ROSA, G. P.; DEPS, V. L. Desatenção do Aluno e Estratégias de Aprendizagem no Contexto Escolar. Revista Científica Interdisciplinar, $\mathrm{N}^{\circ} 4$, v. 2, artigo ${ }^{\circ} 22$, Outubro/Dezembro 
Revista Prática Docente (RPD)

ISSN: 2526-2149

2015. Disponível em: 〈http://dx.doi.org/10.17115/2358-8411/v2n4a22〉. Acessado em 03 mar. 2018.

VYGOTSKY, L. S. A Formação Social da Mente. 6. ed. São Paulo: Martins Fontes Editora Ltda., 1998.

Submetido em: 25 de janeiro de 2018.

Aprovado em: 7 de março de 2018. 